\title{
La ordenación de las acepciones en el NDHE: bases para el establecimiento del criterio genético
}

\author{
The ordering of senses in the NDHE: basis \\ for the establishment of genetic criteria
}

\author{
Mar Campos Souto \\ Universidade de Santiago de Compostela
}

RESUMEN. En este trabajo, tras una presentación sucinta de los criterios de ordenación de acepciones empleados habitualmente en lexicografía, se ofrecerá una explicación somera de los principios que han guiado la ordenación de acepciones en el Diccionario histórico de la lengua española (DHLE) de 1960-1996, repertorio que toma como modelo el Oxford English Dictionary (OED). Posteriormente se enumerarán las características generales del Nuevo diccionario histórico del español $(N D H E)$, un diccionario nativo digital concebido como una base de datos léxica del español $\mathrm{y}$, en particular, se brindará una aproximación a los dos modos de organización de acepciones disponibles en la actualidad en la consulta del diccionario (el cronológico y el de frecuencia). Finalmente, se formulará una primera propuesta para la implementación, en el $N D H E$, del orden genético (entendido como un tipo de orden lógico-lingüístico) a partir del examen de una serie de casos tipo.

Palabras clave: diccionario histórico, ordenación de acepciones, criterio cronológico, criterio de frecuencia, criterio genético.

Data de recepción: 29-11-2019 - Data de aceptación: 17-12-2019.

* La autora forma parte del grupo de investigación Gramática del español de la Universidad de Santiago de Compostela (USC GI-1372), beneficiario de una ayuda para «Consolidación e estruturación de Grupos con Potencial de Crecemento 2017» de la Consellería de Cultura, Educación e Ordenación Universitaria de la Xunta de Galicia (ED431B 2017/39). 
Abstract. In this paper, after a brief presentation of the criteria for the ordering of senses commonly used in lexicography, we will offer a cursory explanation of the principles that have guided the ordering of meanings in the Diccionario histórico de la lengua española (DHLE) of 1960-1996, a repertoire inspired by the Oxford English Dictionary (OED). Subsequently, we will list the general characteristics of the Nuevo diccionario histórico del español (NDHE), a native digital dictionary conceived as a lexical database of Spanish, and we will provide an approximation to the two modes of organization of the meanings that are currently available through the dictionary query (chronological order or order by frequency). Finally, a first proposal will be formulated for the implementation in the NDHE of the genetic order (to be understood as a subcategory of logicallinguistic ordering), taking the examination of a series of standard cases as a point of departure.

Keywords: historical dictionary; ordering of senses; chronological criteria; frequency criteria; genetic criteria

\section{INTRODUCCIÓN}

Estas páginas persiguen presentar una propuesta metodológica para la ordenación genética de las acepciones de un diccionario histórico nativo digital (el $N D H E$ ), que, en la actualidad, permite disponer las acepciones por orden cronológico y de frecuencia, como se comprobará en el apartado 4. Las múltiples posibilidades de acceso al inventario que facilitan los diccionarios digitales dispensan a los lexicógrafos de la exigencia de seleccionar una única pauta organizadora para todos los artículos (o, en todo caso, de la necesidad de explicar la ocasional superposición de criterios), pero, al tiempo, obligan a realizar un proceso riguroso de análisis de los datos para formalizar los criterios de ordenación fijados.

Con este fin, en este artículo se efectuará, en primer lugar, una breve aproximación a los diversos criterios empleados en distintos repertorios, para, a continuación, examinar algunos de los patrones seguidos en el DHLE; la elección de este repertorio viene determinada no solo por cuestiones de índole histórica (ese proyecto de diccionario histórico del español es previo al nacimiento de la lexicografía electrónica y a la irrupción de la lingüística de corpus), sino también por el hecho de que en él se combinan el criterio cronológico y el lógico-lingüístico, a imagen y semejanza del $O E D$. Tras realizar un somero análisis, se enunciarán las características generales del $N D H E$ y se esbozará una primera propuesta para la organización genética de las acepciones de este repertorio, al tiempo que se plantearán otras posibles líneas de trabajo para el futuro (como la determinación de las pautas que pueden regir la organización temática). Por último, las conclusiones permitirán resumir los principales resultados obtenidos en esta investigación. 


\section{CRITERIOS DE ORDENACIÓN DE ACEPCIONES: SÍNTESIS}

Los estudios de metalexicografía coinciden, en general, en señalar que los dos factores más determinantes en la organización de acepciones de un diccionario son el tipo de público al que se dirige la obra y las propias características del repertorio confeccionado (es decir, el género lexicográfico en el que se inscribe) ${ }^{1}$. En esta dirección, Porto Dapena (2002: 225-227) estima que existen cuatro criterios básicos de ordenación: el cronológico o histórico, el etimológico o genético, el lógico o estructural y el de frecuencia; a ellos podrían añadirse otras pautas de importancia menor, como el denominado criterio categorial y el diasistemático (ambos, unidos, corresponden al orden empírico o práctico establecido por Casares 1950)². No debemos olvidar, en todo caso, que la primera resolución que debe tomarse a este respecto en un diccionario radica en optar por una estructura lineal o por una estructura jerárquica; mientras que en el primer caso todas las acepciones pertenecen a un mismo nivel, en el segundo se reúnen en diferentes grupos de acuerdo con relaciones de tipo gramatical o semántico (Rafel i Fontanals 2005: 158-159).

Según el criterio cronológico, las acepciones se clasifican y presentan en función de su primer testimonio, desde la más antigua hasta la más reciente ${ }^{3}$. Como indica Lew (2009: 239), esta ordenación histórica presenta la desventaja de que muchas lenguas carecen de una larga, extensa y continuada tradición escrita, si bien es la preferida por los diccionarios de carácter diacrónico que, no obstante, suelen combinarla con el orden lógico, como sucede en el $O E D^{4}$. Por otra parte, las lagunas de la documentación (o, incluso, la imposibilidad de acceder a todas las fuentes documentales) y

$1 \quad$ La regla que formula Kipfer parece tan razonable e indiscutible como difícil de aplicar: «The basic rule for the lexicographer is to prepare the most useful and informative book possible, using common sense and keeping de reader in mind, above all».

2 Lew (2009: 23) añade el orden textual o pragmático, según el cual las acepciones deberían disponerse siguiendo la estructura típica de cualquier texto, en que se progresa desde la información dada o conocida a la nueva.

3 Gold (1986: 46) considera que es el tipo de ordenación más científico, aunque no está exento de problemas, debido a la existencia de vacíos documentales, lo que a menudo impele a los lexicógrafos a intentar reconstruir la historia de acuerdo con criterios semánticos (es decir, a optar, en cierta medida, por el orden lógico). Un diccionario ideal debería obedecer, según Gold (1986: 48), a una organización histórica combinada con indicaciones de frecuencia y diagramas que muestren la relación entre los distintos significados.

4 Dubois (1984: 238) expone de manera sintética las consecuencias de este tipo de ordenación mixta: «An arrangement based on historical principles was moreover often confused with an ordering based on notional principles, somehow suggesting a logic of history which is subject to universal laws». 
la conciencia de que los significados de la palabra generalmente nacen y viven en la lengua oral antes de registrarse por escrito, añaden otras dificultades al cumplimiento íntegro de este criterio5. Por estas razones, Kipfer (1984: 105) no duda en afirmar que, en los diccionarios históricos de que disponemos, la primera acepción consignada no es, con frecuencia, la más antigua, sino la que se supone que representa el origen semántico (o bien el significado más familiar en la actualidad) ${ }^{6}$.

La opción del orden genético o etimológico implica situar en primer lugar la acepción (o acepciones) atestiguada ya en el étimo inmediato, «y, a partir de ella, tratar de reconstruir el proceso semántico que ha ido dando lugar a las demás acepciones, las cuales no representarán otra cosa que los distintos pasos o eslabones de esa evolución» (Porto Dapena 2002: 225). Aunque podría pensarse que este tipo de ordenación puede resultar coincidente con la cronológica, la realidad muestra que no suele suceder así, puesto que el carácter etimológico de una acepción no garantiza que posea documentación escrita antes que otras no etimológicas. Además, los étimos no suelen ser monosémicos, hecho que también tiene implicaciones para el asunto que nos ocupa, pues

puede ocurrir que una palabra sea polisémica ya en su origen, esto es, etimológicamente, lo que implica que en una ordenación genética haya que registrar ciertas acepciones antes que otras relativamente anteriores, debido a que, de acuerdo con este criterio, habrá que establecer toda la cadena de acepciones que partan de un mismo sentido inicial y, por lo tanto, hasta que se agota esa línea evolutiva no se pasará a la iniciada por otro sentido etimológico y así sucesivamente (Porto Dapena 2002: 226).

En el apartado 4 se expondrán con mayor detenimiento los problemas que plantea el orden genético o etimológico, dado que, entre otras cuestiones, está estrechamente

5 Son, de hecho, esas lagunas las que, según Kipfer (1984: 104), invitan a los lexicógrafos a compaginar el orden histórico y el lógico: «If lexicographers disagree on the historical order of meanings, it is due to poor and/or insufficient data. Yet even in an historical dictionary, the historical order must be combined with the logical order; the main divisions of the semantic description are ordered historically, but senses closely related are grouped within them in a sort of semantic genealogical tree». Y añade: «A reasonable approach in preparing the historical dictionary, then, is to order the materials to bring out the dynamics of lexical development, with attention toward showing the succession and mutual compatibility of meanings».

6 En palabras de Kipfer (1984: 105), «documentation may seldom be sufficient to enable the lexicographer to make more than an educated guess as to the ordering». Por otra parte, como señala Porto Dapena (2002: 225), parece difícil sostener la conveniencia de emplear este tipo de ordenación en los diccionarios sincrónicos o descriptivos, por más que se continúe usando, de manera tácita o implícita, en varios de ellos. 
ligado al grado de certeza sobre la etimología propuesta, así como al nivel de detalle de la información disponible sobre la cronología y los significados del étimo.

La ordenación por la frecuencia (o frecuencia de uso) obliga a colocar primero la acepción más usada y, en último lugar, la menos empleada. Esta pauta organizadora -que ha recibido un gran impulso por el protagonismo de los corpus en la confección de diccionarios y, en particular, en los diccionarios de aprendizaje del inglés (Lew 2009: 241) - presenta como inconveniente el hecho de que varía en función del corpus empleado y, además, no ha demostrado en la práctica la premisa de la que parte: las acepciones más frecuentes deben situarse primero porque son las que buscará el usuario y, por tanto, la consulta será más eficaz y rápida ${ }^{7}$. Por el contrario, puede asegurarse que solo en el caso de que el usuario busque un vocablo completamente desconocido será ciertamente probable que la primera acepción registrada sea aquella sobre la que requiere información (Gold 1986: 44) .

El criterio categorial (Porto 2002: 227) permite ordenar las acepciones en virtud de su adscripción a una determinada clase de palabras o categoría gramatical. Por su parte, el orden diasistemático o empírico actúa en función de «las variedades o sistemas funcionales particulares a que pertenecen dentro de la lengua histórica en cuestión», de tal modo que se sitúan al principio las acepciones generales, comunes

$7 \quad$ Previamente a la confección de los diccionarios basados en corpus, Moliner, en la «Presentación» del DUE, mostraba sus reticencias ante la pretendida superioridad de esta pauta, especialmente en un diccionario general monolingüe: «El sistema de ordenación por grado de frecuencia que algunos defienden frente al expuesto [etimológico] parece a todas luces menos racional; el principal argumento que se aduce a su favor es que la acepción más usual es la que más interés tiene para el lector; esto, no tratándose de diccionarios bilingües está totalmente desprovisto de fundamento, pues se puede asegurar, por el contrario, que estas acepciones son justamente las que nadie va a buscar al diccionario» (1966 [1990]: XXVIII). Por su parte, Porto Dapena (2002: 227) indica que, aunque parece constituir el criterio más adecuado para un diccionario sincrónico, también presenta inconvenientes, pues exige la realización de estadísticas basadas en un corpus (que, por otro lado, debería ser «plenamente representativo del uso real de la lengua»); por consiguiente, la apelación a este criterio se traduce con frecuencia en una subjetiva toma de decisiones del lexicógrafo, guiado más por sus impresiones y percepciones que por datos objetivos (con el «tan socorrido recurso de la conciencia lingüística, algo siempre escurridizo y poco fiable en definitiva»; 2002: 227; véase también Kipfer 1984: 101 para este asunto). A su vez, Casares (1950: 70) y Kipfer (1984: 102) advierten que la rigurosa aplicación de este criterio obliga a realizar actualizaciones continuas de los diccionarios para reflejar los cambios de vitalidad que han experimentado las acepciones entre una edición y otra.

8 Por otra parte, la frecuencia se suele expresar en términos absolutos, concibiendo la lengua como un todo, por lo que la información de frecuencia en pocas ocasiones se refiere a un período determinado (o, en lenguas de amplia extensión geográfica, a un área concreta; véase Gold 1986: 44). Véase también Gorcy (1989: 907). 
a todo el dominio lingüístico, y al final aquellas que se usan en algunas variedades dialectales o sociolectales ${ }^{9}$. Estrechamente relacionados con estos dos criterios está el que Lew (2009: 239) engloba dentro de la etiqueta «otras estrategias restringidas» (aplicables solo a determinados tipos de diccionarios, como el basado en las propiedades sintácticas o gramaticales de las acepciones de una voz, la organización desde las acepciones generales a las restringidas, etc. $)^{10}$.

En un sentido estricto, la ordenación lógica, en palabras de Porto Dapena (2002: 226), «consiste en disponer las acepciones de acuerdo con las relaciones lógicas de adición, inclusión, intersección, etc. contraídas entre ellas». El método lógico (también denominado nocional) opera partiendo de una acepción básica, a la que suceden las restantes; si esa primera acepción presenta un significado concreto, las otras se explicarán como extensiones de ella, pero si muestra un contenido general, el resto de valores de la voz se justificarán mediante la «adición de otras características semánticas» $»^{11}$. El uso de esa pauta se manifiesta en la presencia de expresiones como «en particular», «especialmente», «por extensión»o «por analogía», entre otras (Dubois 1984: y Porto Dapena 2002: 226) ${ }^{12}$. Como recuerdan Hiorth (1954: 414) y Gold (1986: 45), T. Hjelmsquist afirmó que, para J. Murray, el editor del $O E D$, el orden lógico de las palabras originarias del inglés (las denominadas «indigenous words») se entendía como el condicionado por el desarrollo de un significado a partir de otro por las leyes de la asociación; entre ambos significados se produciría algún tipo de salto $^{13}$. El desacuerdo entre la distancia lógica entre las acepciones o en torno a lo que

9 «Precisamente el DRAE, al que siguen muchísimos otros, utiliza estos dos tipos de ordenación, es decir, el criterio empírico, colocando en primer lugar las acepciones de uso corriente, después las anticuadas, las figuradas, las provinciales e hispanoamericanas, y, en último lugar, las técnicas y de germanía. Y en cuanto al orden categorial coloca en primer lugar las correspondientes al adjetivo y luego las de sustantivo y adverbio. Y si se trata de un sustantivo, las acepciones correspondientes al uso de aquél exclusivamente en plural se colocan en último lugar» (2002: 227).

10 En este sentido, Lew (2009: 245) indica que este criterio parece constituir un caso especial de la ordenación lógica. En Lew (2013: 292) se enuncia el criterio de la marcación (o, si se prefiere, de las acepciones marcadas frente a las no marcadas), según el cual se colocan en primer lugar los valores generales, seguidos por los restringidos.

11 Porto Dapena (2002. 226) considera que este criterio resulta útil en la agrupación de las subacepciones, aunque se muestra reticente ante su utilización en el nivel de las acepciones, «al encontrarse más alejadas semánticamente, a veces sin conexión aparente».

12 Sin que, por otra parte, tales fórmulas presupongan la existencia de «fenómenos reales de evolución, sino [...] relaciones de adición, supresión, etc.» (Porto Dapena 2002: 3). Véase también Battenburg (1991: 54).

13 Además, el orden lógico y el histórico serían coincidentes, con frecuencia, en este tipo de vocablos. 
constituye un salto semántico justificaría, no obstante, las discrepancias observadas en el proceder de los lexicógrafos ${ }^{14}$.

Aunque excede los límites de este trabajo exponer un examen pormenorizado de sus méritos y deméritos, todas las pautas de ordenación presentan virtudes y flancos débiles ${ }^{15}$. Por lo que se refiere, en particular, al criterio lógico, Lew (2009: 243 y 2013: 293) indica que la presunción de que los significados se pueden organizar según este principio implica asumir que existe un significado central, del que derivan los demás (por extensión, especialización o generalización), así como defender la existencia de una estructura jerárquica entre las acepciones de un vocablo ${ }^{16}$; para este autor, además, la lectura de la bibliografía especializada revela que el criterio lógico está envuelto en una considerable confusión o vaguedad ${ }^{17}$. Dubois (1984: 238), a su vez, advierte que esta interpretación de las relaciones semánticas conlleva una suerte de «precedencia metafísica», puesto que, por ejemplo, se pasa de lo concreto a lo abstracto o de los seres vivos a los objetos ${ }^{18}$. En un estudio ya clásico, Hiorth (1954: 414) mostró que, aunque en algunos diccionarios se afirmaba haber organizado las acepciones de acuerdo con esta pauta, en realidad el manejo del criterio nocional era vago, puesto que los lexicógrafos eran incapaces de explicar los motivos que regían esta ordenación (aun después de aplicarla). La crítica al orden lógico de Hiorth (en buena parte, asumida por Kipfer 1984) se sustenta en el hecho de que constituye una afirmación (o, incluso, una presuposición) sobre la evolución histórica de los significados que no

14 Gold (1986: 45) considera que Murray estaba intentando emular, en semántica (aunque quizás sería más adecuado decir «en lexicografía») las leyes que formularon los neogramáticos para la evolución de los sonidos.

15 Como afirma Lew (2009: 246), «an expectation that a single strategy might be optimal in all circumstances is naïve and unrealistic». Y ello, fundamentalmente, por dos motivos: en primer lugar, no parece que un único tipo de orden satisfaga mejor las necesidades de los usuarios y las funciones propias del diseño de un diccionario que otro; en segundo lugar, la práctica lexicográfica muestra la necesidad de dotar de un tratamiento particularizado, individual, a ciertos elementos de cada diccionario.

16 Véase también Gorcy (1989: 906-907) y Gold (1986: 45). En el orden lógico, según Moeerdkij (2003: 285), la relación entre los significados centrales y los periféricos se puede concebir de distintos modos, que se resumen a continuación: la relación que va del significado general al específico, del central al periférico, del literal al no literal (o metafórico), del concreto al abstracto, y del original al derivado.

17 Lew (2013: 293) concluye que tanto el denominado orden lógico como la ordenación psicológicamente significativa «represent intuitive attempts at respecting the dictionary entry as a coherent text [...], rather than seeing it as a loose amalgamation of independent senses».

18 En esta misma dirección, Silva (2000: 93) recuerda que, en la ordenación de las acepciones del $O E D$, se emplean criterios lógicos: lo concreto precede a lo abstracto, lo religioso a la secular, lo literal a lo figurado, etc. 
se basa en una investigación real, sino en teorías (explícitas o implícitas), que varían entre distintos lexicógrafos, asumidas como defendibles o posibles ${ }^{19}$. Gold (1986: 45) se muestra especialmente crítico con las conexiones establecidas entre acepciones pertenecientes a distintos períodos históricos, áreas geográficas o niveles de uso. Por último, Kipfer (1984: 103) considera que los usuarios de un diccionario deben poder consultar las acepciones o bien de acuerdo con el orden histórico, o bien en virtud del orden de frecuencia de uso, acaso complementado con el orden lógico, solo con fines aclaratorios o explicativos; asumir otro criterio organizador en exclusiva (y, en particular, el orden lógico) conduciría, a su juicio, a un exceso de subjetividad en la presentación de los datos.

En resumen, en la elaboración de diccionarios se han empleado distintos patrones para organizar las acepciones de las voces polisémicas; en tanto que el criterio de frecuencia de uso ha desempeñado el papel protagonista en los diccionarios de aprendizaje (especialmente del inglés) y ha reclamado su superioridad en los diccionarios descriptivos y sincrónicos, el orden cronológico y el lógico parecen haber gozado de las preferencias de los redactores de los diccionarios históricos. Todos, en su aplicación práctica, muestran sus fortalezas y debilidades, aspectos que no han pasado desapercibidos ni a los ojos de los lexicógrafos ni al exigente cedazo de la crítica lexicográfica y de la teoría de la lexicografía.

\section{LOS CRITERIOS DE ORDENACIÓN DE ACEPCIONES EN LA LEXICOGRAFÍA HISTÓRICA GENERAL DEL ESPAÑOL: EL DHLE DE 1960-1996}

Entre 1933 y 1936 se publican los dos tomos del primer Diccionario histórico de la Real Academia Española, obra en que la ordenación de las acepciones sigue la misma pauta establecida en el DRAE de 1925, por lo que su análisis se excluye de este estudio ${ }^{20}$. En cambio, los criterios cronológico y lógico-lingüístico determinan la organización de los significados en el DHLE de 1960-1996. Como se expondrá a continuación, las bases teóricas y metodológicas que guían esta estructuración se explican con detalle en el «Prólogo» al primer tomo de esta obra, si bien la reflexión

\footnotetext{
19 La conclusión no puede ser más rotunda: «The application of the concept of logical order also varies among lexicographers, as the application is based on the knowledge of the lexicographers themselves. This kind of treatment should not be accepted in these scientific times» (Kipfer 1984: 102).

20 En la sección correspondiente a los materiales inéditos del repertorio (cía-efélide) se reproducen, con algunas modificaciones, los artículos de la decimosexta edición del diccionario usual.
} 
en torno a este asunto encuentra un punto de apoyo esencial en los trabajos de Casares $(1950)^{21}$.

Casares (1950: 67) identifica cuatro principios en la ordenación de acepciones: el empírico, el genético, el lógico y el histórico (además del analógico o por ideas, seguido en una de las secciones de su Diccionario ideológico de la lengua española $)^{22}$. A su juicio, no cabe duda de la mayor solidez del principio histórico, el único que garantiza presentar «una obra lexicográfica concebida con criterio científico y que aspire a tener validez para varias generaciones» (1950: 70). El criterio histórico (1950: $68,70)$ se formula en los siguientes términos: «dar primeramente la etimología del vocablo, después la acepción más próxima al origen, aunque a veces sea inusitada, y después otras acepciones».

En su defensa de la preeminencia del «método histórico», Casares prueba su validez en el estudio de la palabra orden, sin eludir previamente la enumeración de dificultades que la aplicación de este criterio puede presentar. La imagen de un árbol invertido le sirve para poner de manifiesto algunos de los escollos que aguardan a los lexicógrafos, pues implica que solo hay un tronco y una raíz, si bien la historia demuestra que, en realidad, la raíz puede bifurcarse y que no siempre se puede decidir cuál de los tallos de la planta es el que se ha convertido en el tronco; y ello, fundamentalmente, porque los redactores de un diccionario de este tipo se sitúan ante fragmentos de la historia que deben interpretar. Casares describe del siguiente modo

${ }_{21}$ Debe recordarse que Casares fue el primer director del Seminario de lexicografía de la Real Academia Española, organismo encargado de la elaboración del Diccionario histórico, según lo dispuesto en el decreto de creación publicado en el Boletín Oficial del Estado del 27 de noviembre de 1946.

22 Se entiende por método empírico el seguido en el diccionario usual de la Real Academia Española, que sitúa en primer lugar las acepciones generales («de uso vulgar y corriente»), seguidas de las que presentan algún tipo de restricción cronológica, diastrática, diatópica o diatécnica. El criterio empírico se entiende como un orden de frecuencia, aquel que "piensa en la inmensa mayoría de los lectores» y cuyo «ideal es anticiparse, adivinar lo que probablemente buscará el lector y servírselo en primer término sin rodeos, sin fatiga y sin pérdida de tiempo» (1950: 69). Entre los inconvenientes de este procedimiento, Casares menciona la inexistencia de una «estadística del uso» que revele cuál es el significado más corriente, por lo que este orden acaba siendo arbitrario en muchos casos, entre otros motivos porque la aplicación coherente de ese criterio obligaría a realizar nuevas ediciones o actualizaciones frecuentes de los repertorios, con una reorganización casi permanente de las acepciones identificadas en cada artículo (Casares 1950: 69-70). Gold (1986: 45), por su parte, insiste en la heterogeneidad de los elementos incluidos bajo el paraguas del método empírico, en el que coexisten datos relativos a la frecuencia, a la vitalidad cronológica y a la distribución espacial de una determinada acepción, así como a su uso en un sociolecto o en un registro concreto. 
la improbable situación ideal que llevaría a la confección de un artículo impecable (tanto atendiendo al principio histórico como al lógico):

Suponiendo que tuviéramos ante los ojos la serie ininterrumpida de los significados que ha ido asumiendo un signo verbal desde que apareció en nuestra lengua hasta el momento en que se redacta el Diccionario, y suponiendo también que en esa serie de significados derivasen los unos de los otros formando una cadena semántica, tendríamos un criterio de ordenación que sería al mismo tiempo lógico y genético. Después, colocadas las acepciones por el orden cronológico de las fechas en que cada una de aquellas apareció por primera vez en la lengua, podría ocurrir que este orden coincidiese con el de la serie genética, lo que nos permitiría redactar un artículo ideal y, al propio tiempo, tan objetivo y convincente, que pondría al lexicógrafo por encima de toda discusión (Casares 1950: 72).

La realidad muestra el carácter inalcanzable (casi tantálico) de ese artículo ejemplar, por diversos motivos:

- Varios significados pueden haber existido únicamente en la lengua oral, sin dejar rastro en los testimonios escritos.

- El étimo es, con frecuencia, polisémico, y su evolución semántica puede ser paralela, divergente (e incluso inversa) a la observada posteriormente en español; ese carácter polisémico obliga a identificar distintas series de significados que, además, pueden ser «tantas cuantas sean las acepciones del étimo transmitidas a la lengua heredera, donde a veces se cruzan o se bifurcan, dando lugar a nuevas series» (1950: 72-73).

- Por último, debe tenerse presente que «el orden cronológico en que las acepciones hacen su aparición en castellano parece que debiera remontarnos invariablemente hasta enlazar con la etimología, pero este supuesto resulta desmentido con harta frecuencia» $(1950: 73)^{23}$.

La palabra orden le permite a Casares ofrecer un modelo de aplicación del método de trabajo: tras analizar la distribución en series y acepciones del latín ORDO, traza un cuadro sinóptico en el que se resume la trayectoria de la palabra española desde

23 En suma, como apunta Casares, estas advertencias sirven para desengañar a quienes piensen que «en el método histórico se ha encontrado una panacea o un procedimiento automático que excluye todo elemento conjetural. Ni el sistema resuelve todos los problemas que preocupan al lexicógrafo, ni su adaptación a la variedad de los casos que se presentan en la práctica es cosa que se pueda regular de antemano mediante una casuística general». Y recuerda el principio enunciado en el prólogo del $O E D$ (al que nos referiremos más adelante) para aquellos casos en que se detectan notorias discrepancias entre el orden genético y el cronológico: «Hay que tratar cada palabra de la manera que parezca más adecuada para presentar los hechos de su historia y de su uso» (1950: 73). 
la lengua madre (véase cuadro 1); en él se observa que las treinta y dos acepciones se agrupan en tres series semánticas (divididas en siete grupos semánticos «homogéneos»), al tiempo que los significados que suponen una continuación de los latinos se identifican mediante una letra del alfabeto griego, información que permite efectuar un cotejo entre los valores de la voz latina y la española.

\begin{tabular}{|c|c|c|c|c|c|c|c|}
\hline & & \multicolumn{6}{|c|}{ ORDEN } \\
\hline & & \multicolumn{2}{|r|}{ I } & \multirow{2}{*}{ 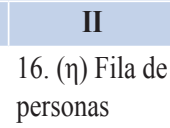 } & \multicolumn{3}{|c|}{ III } \\
\hline & & $\begin{array}{l}\text { 1.- }(\alpha) \text { Fila de } \\
\text { cosas }\end{array}$ & $\rightarrow$ & & IIIa $\leftarrow$ & $\begin{array}{l}\text { 10. }(\lambda) \text { Orden } \\
\text { abstracto }\end{array}$ & $\rightarrow \quad$ IIIb \\
\hline & & $\begin{array}{l}\text { 2.- }(\zeta) \text { Serie } \\
\text { temporal }\end{array}$ & & $\begin{array}{l}\text { 17. }(\theta) \\
\text { Formación } \\
\text { militar }\end{array}$ & $\begin{array}{l}24 .(v) \\
\text { Criterio del } \\
\text { orden }\end{array}$ & $\begin{array}{l}\text { 21. }(\mu) \\
\text { Colocación } \\
\text { adecuada }\end{array}$ & $\begin{array}{l}\text { 29. Plan o } \\
\text { designio }\end{array}$ \\
\hline & & 3. ( $\beta$ ) Gradas & $\mathrm{Ib}$ & $\begin{array}{l}\text { 18. (1) Unidad } \\
\text { táctica }\end{array}$ & $\begin{array}{l}\text { 25. (v) Orden } \\
\text { supremo }\end{array}$ & $\begin{array}{l}\text { 22. Relación } \\
\text { recíproca }\end{array}$ & $\begin{array}{l}30 . \\
\text { Procedimiento }\end{array}$ \\
\hline & & $\begin{array}{l}\text { 4.- }(\gamma) \\
\text { Condición } \\
\text { social }\end{array}$ & $\rightarrow \begin{array}{l}13 . \text { Clase de } \\
\text { las cosas }\end{array}$ & $\begin{array}{l}\text { 19. (к) Mando } \\
\text { militar }\end{array}$ & $\begin{array}{l}\text { 26. (v) Orden } \\
\text { moral }\end{array}$ & $\begin{array}{l}\text { 23. Orden } \\
\text { arquitectónico }\end{array}$ & 31. Instrucciones \\
\hline & & & $\begin{array}{l}\text { 14. Género } \\
\text { (Hist. Nat.) }\end{array}$ & & $\begin{array}{l}\text { 27. (v) Norma } \\
\text { positiva }\end{array}$ & & 32. Mandato \\
\hline & & & $\begin{array}{l}\text { 15. Grado } \\
\text { (Mat.) }\end{array}$ & & $\begin{array}{l}\text { 28. Regla } \\
\text { monástica }\end{array}$ & & \\
\hline & & $\begin{array}{l}\text { 5. }(\delta) \text { Clase } \\
\text { social }\end{array}$ & & & & & \\
\hline $\begin{array}{l}\text { 10. Orden } \\
\text { religiosa }\end{array}$ & $\rightarrow$ & $\begin{array}{l}\text { *Ordo } \\
\text { sacerdotum }\end{array}$ & & & & & \\
\hline \multirow{2}{*}{\multicolumn{8}{|c|}{$\begin{array}{l}\text { 11. Orden } \\
\text { militar } \\
\text { 12. Orden } \\
\text { civil }\end{array}$}} \\
\hline & & & & & & & \\
\hline & & $\begin{array}{l}\text { 6. Grados del } \\
\text { sacerdocio }\end{array}$ & & & & & \\
\hline & & $\begin{array}{l}\text { 7. Grados } \\
\text { angélicos }\end{array}$ & & & & & \\
\hline & & $\begin{array}{l}\text { 8. Sacramento } \\
\text { del orden }\end{array}$ & & & & & \\
\hline & & $\begin{array}{l}\text { 9. Sacramento } \\
\text { del matrimonio }\end{array}$ & & & & & \\
\hline
\end{tabular}

CUADRO 1. Orden 
La posibilidad de que surja un conflicto entre el orden genético (esto es, el «encadenamiento lógico que pretende ilustrar la manera en que cada significado ha podido nacer del anterior») y el histórico (cronológico), obliga a concluir que tal divergencia nos sitúa ante el «margen de incertidumbre» que pervive todavía en la lexicografía histórica, que no ha logrado alcanzar una respuesta adecuada a este desacuerdo ${ }^{24}$. A nuestro juicio, la principal innovación del modelo de Casares radica en la vinculación que se establece entre las acepciones de la voz española y las de la voz madre, latina, cuyas evoluciones semánticas pueden observarse en paralelo ${ }^{25}$. Además, el anhelo de poder incluir, en cada acepción, una «cifra indicadora de la frecuencia con que se ha usado», contribuye a completar el modelo de ordenación de acepciones propuesto por Casares, en el que se emplean, con funciones y valores diversos, criterios semánticos o conceptuales, genéticos e históricos (a los que debería añadirse el criterio de frecuencia de uso).

En la Muestra del Diccionario histórico de 1951 se percibe ya la puesta en práctica de algunos de los presupuestos enunciados por Casares; de este modo, en artículos como el de abalanzar se distinguen dos series o grupos semánticos: el del movimiento de los platillos en la balanza (en la que se incluyen nueve acepciones) y el del equilibro de los platillos en la balanza (con una única acepción) ${ }^{26}$. Sin embargo, las acepciones no muestran explícitamente su conexión con las de la palabra de la que proceden (véase, a este respecto, baldón), diferencia que marca una distancia relevante con la propuesta de Casares y, al tiempo, una mayor cercanía a las pautas seguidas en el $O E D$.

Posteriormente, en el «Prólogo» al primer tomo del DHLE (publicado en 1972 y redactado por Rafael Lapesa) se dedica un apartado la «Ordenación interna de los artículos»; tras afirmar que «la dificultad mayor en la organización de un artículo consiste en la ordenación de las acepciones», se advierte que en no pocas ocasiones

24 Véase, a este respecto, las apreciaciones de Casares (1950: 88-89) sobre la estructura del artículo consagrado a order en el $O E D$.

25 Casares reivindica también el establecimiento de series y grupos semánticos homogéneos (práctica efectuada previamente en otros diccionarios históricos, como el $O E D$ ), puesto que «facilita en gran manera la concordancia del «orden genético» con el «orden histórico» dentro de dichos grupos, lo que sería imposible de lograr en una larga serie heterogénea»; además, la «precedencia cronológica» solo se toma en consideración «cada vez que se inicia un grupo, y sin preocuparse de lo que sucede en los restantes» (1950: 89).

26 Agrupaciones similares se pueden advertir en abaldonar, abandonar, baldón y baldonar. En el $D H L E$, en cambio, se identifican siete acepciones en la primera serie de abalanzar, dado que dos de las incorporadas en la Muestra pasan a considerarse subacepciones ('arrollar' y 'arriesgar, poner en peligro'). 
el orden cronológico impuesto por los testimonios acopiados entra en contradicción «con el encadenamiento originario que es preciso suponer entre unos significados y otros». Lapesa señala que en el $D H L E$ se opta por disponer las acepciones en función del criterio cronológico, «pero siempre con un margen de libertad», puesto que, por una parte, no se puede asegurar que los primeros testimonios localizados en la documentación manejada correspondan, en realidad, a la primera aparición de un determinado significado y, por otra, porque deben tomarse en consideración otros factores, como la continuidad de los valores atestiguados en la lengua de origen de cada palabra. La serie, la subserie, la acepción y la subacepción se conciben como «divisiones semánticas de distintos grados»; el nivel más alto en la jerarquía está ocupado por la serie, que agrupa acepciones emparentadas (ordenadas, a su vez, cronológicamente, como norma general). Por consiguiente, aunque el criterio cronológico disfruta de primacía, la afinidad semántica entre las acepciones permite reunir aquellas que se consideran emparentadas de manera evidente.

No resulta en absoluto novedoso afirmar que esta organización del DHLE tiene su antecedente inmediato en el $O E D$. En efecto, en el $O E D$ se insiste en la necesidad de que el diccionario sea capaz de descubrir y reflejar el desarrollo semántico de las palabras. En una situación ideal (con testimonios abundantes y representativos de cada época), la sucesión histórica de las acepciones sería paralela a un desarrollo lógico; sin embargo, en ocasiones la realidad es mucho más compleja y nos enfrenta a la necesidad de representar la evolución de los significados de una palabra de una forma ramificada (no lineal):

In exhibiting this in the Dictionary, that sense is placed first which was actually the earliest in the language: the others follow in the order in which they appear to have arisen. As, however, the development often proceeded in many branching lines, sometimes parallel, often divergent, it is evident that it cannot be adequately represented in a single linear series. Hence, while the senses are numbered straight on 1, 2, 3, \&c., they are also grouped under branches marked I, II, III, \&c., in each of which de historical order begins afresh. Subdivisions of the senses, varieties of construction, \&c., are marked a, b, c, \&c.; subdivisions of these, which rarely occur, (a.), (b.), (c.)... So far for words of which the senses have been developed in English itself (Murray et alii 1884 [1978]: XXXI) ${ }^{27}$.

$27 \quad$ Véase también Silva (2000: 91-92) para la aplicación combinada del orden lógico y el histórico en el $O E D$; como se recuerda en este trabajo, se ha puesto en duda el carácter histórico de la metodología aplicada en este diccionario precisamente por la importancia conferida a la ordenación lógica, que relega a un segundo lugar la evidencia aportada por los testimonios espigados en las fuentes documentales. 
En los vocablos ingleses procedentes de otras lenguas, como el latín, en el $O E D$ se advierte que, con gran frecuencia, el orden histórico en que se registran las acepciones no coincide con el «natural order» en que se desarrollaron en la lengua original, sino que estas palabras suelen atestiguarse primero con un valor figurado o especializado; cuando el orden lógico de los significados de la voz en la lengua madre y el orden histórico en la lengua receptora son divergentes, el $O E D$ opta por tratar cada palabra «in the way which seems best suited to exhibit the facts of its own history and use» (Murray et alii 1884 [1978]: XXXI) ${ }^{28}$.

En su estudio sobre alma y ánima en el DHLE, Lapesa (1980) explica minuciosamente la metodología seguida en la aplicación de los criterios cronológico y lógico-lingüístico (semántico) en los artículos dedicados a estos vocablos. En el artículo alma, en que se distinguen ocho series (con una subserie en la última) y treinta y siete acepciones, se indica que el principio cronológico «determina la sucesión de la series entre sí de las acepciones dentro de cada serie, de las subacepciones dentro de cada acepción, de los grupos de locuciones según su función gramatical y de las locuciones dentro de cada grupo» (1980: 188), si bien Lapesa ya advierte que la serie I (representada por una única acepción: 'elemento psíquico o espiritual de los seres humanos y principio inmaterial de su vida') no se atestigua hasta el Cantar del Mio Cid (datado c1140), en tanto que las series II ('como superviviente de la muerte temporal') y III ('como órgano de la afectividad') se registran previamente. Esta discordancia se hace explícita ya en el DHLE (s. v.), donde se señala que se sitúa «esta serie y acepción porque, si bien hay testimonios anteriores de la series II y III, estas presuponen la existencia de la I, fundamental entre las heredadas del latín anima». De este modo, la conexión con el significado etimológico de la voz actúa, de algún modo, como pauta ordenadora en la microestructura de este repertorio.

Esa necesaria conciliación entre el orden cronológico y la presentación del «desarrollo semántico diacrónico» persuade a Lapesa de la conveniencia de agrupar de distinto modo las acepciones de ánima, vocablo que, por otra parte, «es un cultismo que se infiltra en el uso romance de los doctos por recuerdo del latín y se extiende luego, en mayor o menor grado según las acepciones, a la lengua general», frente a alma, que «pertenece a la herencia de ininterrumpida tradición oral» (1980: 189). En consecuencia, las cuatro primeras series de alma se convierten en cuatro ramas de una serie en ánima, para armonizar la datación de las acepciones con la explicación

28 En este sentido, Silva (2000: 93) concluye que, para Murray, el orden lógico tiene preferencia sobre el cronológico, salvo en el caso de voces tomadas de otras lenguas, en que se priorizará la ordenación histórica. 
aportada sobre la evolución semántica de la palabra (o, si se prefiere, en palabras de Lapesa 1980: 188, con las «exigencias de la continuidad semántica»). En el cuadro 2 se sintetizan ambas propuestas de ordenación ${ }^{29}$ :

\begin{tabular}{|c|c|}
\hline ALMA & ÁNIMA \\
\hline $\begin{array}{l}\text { Serie I. Acep. 1: Elemento psíquico o espiritual de } \\
\text { los seres humanos y principio inmaterial de su vida } \\
(c 1140)\end{array}$ & $\begin{array}{l}\text { I. Con referencia al elemento psíquico o espíritual de } \\
\text { los seres humanos. } \\
\text { A. Alma superviviente al cuerpo. } \\
\text { AA. Con referencia a la suerte que en sus postrimerías } \\
\text { quepa al alma de una persona (acep. 1). Acep. 1. Con } \\
\text { referencia a la suerte que en sus postrimerías quepa al } \\
\text { alma de una persona (1195) } \\
\text { AB. Con referencia al alma de un difunto, presente, } \\
\text { recordada o invocada en algún tiempo o lugar (aceps. } \\
\text { 2-6). Acep. 2: Aparecido, espectro de un difunto (1492) } \\
\text { AC. Acep. 7. Disposiciones del testador para satisfacer } \\
\text { obligaciones y otros sufragios (1534). }\end{array}$ \\
\hline $\begin{array}{l}\text { Serie II (aceps. 2-3). Acep. 2: Elemento espiritual e } \\
\text { inmaterial del ser humano, que sobrevive tras la muerte } \\
\text { corporal }(c 1140) \text {. }\end{array}$ & $\begin{array}{l}\text { B. Elemento inmaterial de los seres humanos y } \\
\text { principio de su vida. Acep. } 8 \text { : Elemento psíquico } \\
\text { o espiritual de los seres humanos y principio } \\
\text { inmaterial de su vida. En los textos aparece frec. en } \\
\text { contraposición con el cuerpo, y de ordinario como } \\
\text { creación de Dios e inmortal (1120) }\end{array}$ \\
\hline $\begin{array}{l}\text { Serie IV (aceps. 6-13). En relación con las actividades } \\
\text { intelectuales y morales del ser humano. Acep. } 6 \text {. } \\
\text { Órgano de las actividades intelectuales y morales del } \\
\text { ser humano, así como de su vida religiosa }(c 1140) \text {. }\end{array}$ & $\begin{array}{l}\text { C. En relación con la vida intelectual, moral y religiosa } \\
\text { del ser humano (aceps. 9-13). Acep. 9: Órgano de las } \\
\text { actividades intelectuales y morales del ser humano, } \\
\text { así como de su vida religiosa. Suele entenderse como } \\
\text { responsable de la conducta individual y susceptible de } \\
\text { salvación o condena tras la muerte (1224). }\end{array}$ \\
\hline $\begin{array}{l}\text { Serie III. (aceps. 4-5). 4. Órgano de la vida afectiva, } \\
\text { del sentimiento y de la imaginación. Lo más íntimo y } \\
\text { profundo del ser humano (c1110?) }\end{array}$ & $\begin{array}{l}\text { D. En relación con la vida afectiva (aceps. 14-15). } \\
\text { Acep. 14. Órgano de la vida afectiva, sede del } \\
\text { sentimiento y de la imaginación; lo más íntimo y } \\
\text { profundo del ser humano (c1400). }\end{array}$ \\
\hline
\end{tabular}

CUADro 2. Alma y ánima en el DHLE

En conclusión, el criterio lógico-lingüístico, entendido en clave semántica, constituye el factor determinante en la agrupación de las acepciones (en series y subseries), mientras que el criterio cronológico, en este tipo de artículos complejos, actúa como la pauta de organización en lo referente a la prelación entre las diferentes series, así como entre las diversas acepciones de cada grupo. La polisemia, por tanto, obliga

29 Solo se incluye la primera acepción de cada serie o subserie. 
a reconstruir o a establecer la «red de filiaciones» — en palabras de Seco (1980: 41) - por medio de una «ordenación ramificada» que otorga una «perspectiva tridimensional» del desarrollo histórico de la voz, frente a las más habituales estructuras lineales ${ }^{30}$. Las representaciones o diagramas jerarquizados que se deducen de este modo de proceder se asemejan a los estemas, con los que la crítica textual muestra la filiación entre los distintos testimonios de una misma obra, con el objetivo último de reconstruir el texto original (que, por otra parte, pocas veces corresponde a un testimonio concreto). Como ya se ha señalado con anterioridad, frente al artículo modelo de Casares (orden), en el DHLE, en cambio, no se muestra de manera visible y evidente la vinculación con las acepciones de la palabra madre de los vocablos del español, por más que se aluda en ocasiones a esa conexión.

\section{LA ORDENACIÓN DE ACEPCIONES EN EL NDHE}

El NDHE se define como un diccionario nativo digital que persigue presentar un estudio minucioso de la historia del léxico español de acuerdo con una metodología relacional, puesto que se aproxima al análisis de la biografía de cada voz atendiendo de manera prioritaria a la red de relaciones morfogenéticas y semánticas que establece con los otros vocablos del españo ${ }^{31}$. Desde sus planteamientos iniciales (Pascual Rodríguez y García Pérez 2007, 28 y 38), el NDHE se concibió como una base de datos de acceso público en internet; entender el diccionario como una base de datos implica que este repertorio, además de estar llamado a ser el diccionario exhaustivo o total del español (es decir, su tesoro), se transforma realmente en un recurso — más que en un único producto- que permite construir, a partir de los datos contenidos en él, diversos tipos de inventarios lexicográficos, así como formular consultas muy pormenorizadas ${ }^{32}$.

30 Puede verse, en este sentido, su explicación de la agrupación en cuatro ramas de las cinco acepciones de aleluya en el DHLE (Seco 1980: 42), haciendo mención explícita del origen hebreo de la primera serie atestiguada («Con referencia a la exclamación hebrea de júbilo que aparece en los textos sagrados, y al tiempo pascual en que la Iglesia la usa especialmente»). Véase también Seco (1995: 210-211). Un cotejo entre la organización de los artículos accidente del DHLE y accident del TLF puede consultarse en Marcos Marín (1975).

31 Tras su última actualización, realizada en septiembre de 2020, el NDHE cuenta con 5610 artículos.

32 Véase, para esta cuestión, Campos Souto (2015: 73-76). Del NDHE podrían extraerse, por ejemplo, un diccionario de sinónimos, un diccionario del español de un país o de un período cronológico determinado (seleccionando aquellas palabras que solo estén atestiguadas en textos redactados por autores de esos países o en obras del período acotado) o un diccionario sintagmático, con información combinatoria (eligiendo, por ejemplo, aquellos artículos que contengan esquemas sintácticos en los que, a su vez, se incorporen datos sobre restricciones léxicas). Por otra parte, 
El NDHE, en suma, constituye una de las manifestaciones más evidentes de la radical transformación experimentada por la lexicografía en los últimos años, fruto de la actuación conjunta de varios factores, entre los que cabe destacar el surgimiento de la informática, el desarrollo de la lingüística de corpus (y su papel determinante en la confección de diccionarios; véase Rojo 2009) y los progresos efectuados en los estudios metalexicográficos y en la investigación lingüística sobre el léxico.

La condición digital del NDHE exime a los lexicógrafos de la necesidad de optar por un único modo de presentación de los datos y, en particular, de una única disposición de las acepciones que conforman cada artículo. Esa mayor libertad presenta, como reverso de la medalla, la necesidad de someter las posibles pautas de organización de los significados identificados a una rigurosa formalización, con el fin de poder llevar a cabo los desarrollos informáticos que posibiliten aplicar los principios ordenadores de una forma automática a todas las monografías del diccionario y facilitar, así, la publicación dinámica de las informaciones contenidas en él.

\subsection{Criterios cronológico y de frecuencia}

La herramienta de visualización del $N D H E$ solo permite, en la actualidad, efectuar consultas básicas, con algunas posibilidades de interacción por parte del usuario; la ordenación por defecto que presentan las acepciones de cada artículo es la cronológica (partiendo de la más antigua a la más reciente), discriminando entre acepciones léxicas y lexicográficas (esto es, registradas solo en diccionarios, vocabularios, glosarios, etc. (3). $^{33}$.

No parece necesario subrayar que la ordenación histórica o cronológica descansa sobre la correcta datación de los textos empleados en el diccionario; a este respecto, conviene recordar los problemas de fechación de algunas de las obras incorporadas a los corpus sobre los que se erige el $N D H E$ (en particular, el $C D H$, con sus tres capas de consulta: el $C D H$ nuclear, la extensión diacrónica — conformada por textos procedentes del CORDE - y la extensión sincrónica —en que se da cabida a obras del $C R E A$ ), así como la necesaria distinción entre texto y testimonio (y, en consecuencia,

el diseño de la base de datos está planteado de tal modo que, en un futuro inmediato, se puedan efectuar consultas más refinadas; así, se podría pedir, por ejemplo, un listado de las voces que presenten el sufijo (o la terminación) - ería que remitan a un étimo inmediato francés y cuyo primer testimonio se registre a partir del año 1750 (con inclusión, además, de los dos primeros ejemplos y de información sobre las relaciones de identidad o inclusión que mantienen con otras palabras en ese período). Para una descripción más detallada del NDHE, véase Pascual (2015), Salas Quesada y Torres Morcillo (2011 y 2015) y Campos Souto (2016).

33 Las acepciones lexicográficas se sitúan tras las léxicas, al final de cada artículo; su ordenación se efectúa también en virtud de un criterio cronológico. 


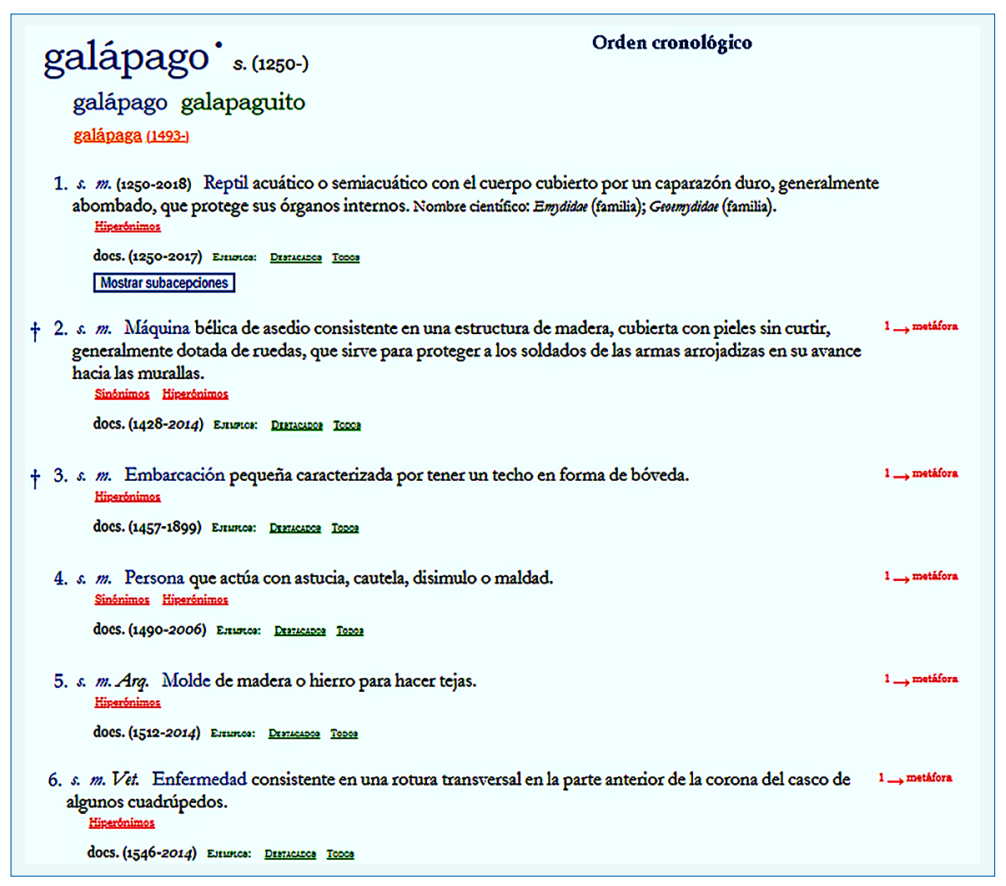

FiguRA 1. Orden cronológico (galápago)

entre la fecha de redacción de la obra y la fecha del manuscrito o impreso en que se conserva $)^{34}$. En este sentido, aunque los ejemplos se ordenan en función de la fecha de redacción de la obra, en el $N D H E$ está previsto poder implementar la ordenación cronológica a partir de la fecha del testimonio base del texto incluido en los corpus ${ }^{35}$. Mientras esa opción no esté disponible, en los resúmenes (que presentan, de un modo sintético, los principales acontecimientos en la vida de una palabra) se anotan, cuando se estima relevante, observaciones sobre la datación de los testimonios ${ }^{36}$.

34 Véase, para estas cuestiones, Pascual (2016), Campos Souto (2016 y 2018) y Rodríguez Molina y Octavio de Toledo y Huerta (2017).

35 El $C D H$ permite ordenar las concordancias por la fecha del testimonio (y no solo de la obra), si bien esta posibilidad de consulta solo se extiende, en este momento, a las obras de la etapa medieval del $C D H$ nuclear.

36 Así, por ejemplo, en citolero, a se indica que la voz «se documenta por primera vez en 1293, en Castigos. BNM Ms. 6559 (conservado en un manuscrito del siglo XV) y su aparición en los textos es ciertamente esporádica, aunque constante durante el siglo XV» (NDHE, s. v.). Véase también violero, $a^{1}$. 


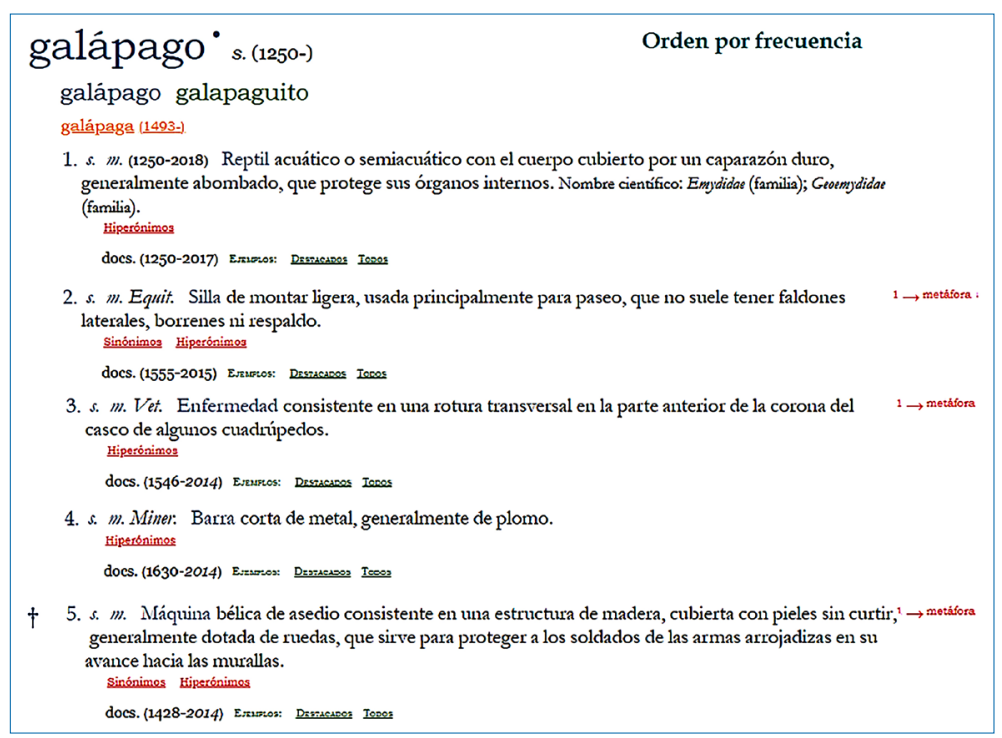

FIGURA 2. Orden por frecuencia (galápago)

Los usuarios disponen, además, de la posibilidad de ordenar las acepciones por su frecuencia absoluta, un criterio que, no obstante, resulta problemático, pues está estrechamente ligado a la selección de las fuentes documentales que suministran los testimonios en que se sustenta el análisis de las palabras ${ }^{37}$.

Sin duda, lo ideal sería, además, poder ofrecer datos sobre la frecuencia relativa o, en todo caso, asumir la propuesta de Gold (1986: 44) y mostrar la información de frecuencia tanto para períodos concretos como para toda la historia del español, para poder percibir así las oscilaciones en la vigencia o vitalidad de una determinada acepción.

37 Como observan Salas Quesada y Torres Morcillo (2015), la información sobre frecuencia debe entenderse como una orientación, puesto que sus resultados están determinados por el diseño de los corpus base del diccionario (y, en especial, del $C D H$ nuclear). Además, en las palabras que no se registran en los corpus (pero que han de redactarse por su pertenencia a un determinado campo o a una familia léxica concreta) o en aquellas que presentan un número escaso de testimonios, se recurre con frecuencia a otras fuentes (como las bibliotecas y hemerotecas digitales), «lo que puede contribuir también a trazar un perfil distorsionado de su vitalidad» (2015: 60). En este sentido, Campos Souto (2018) muestra la relevancia de estas fuentes digitales para la localización de primeros testimonios de las voces en el español de los últimos siglos, aunque también pone de manifiesto ciertas desventajas, como la infrarrepresentación del español americano frente al europeo y, especialmente, la ausencia de lematización y de información sobre la fecha de redacción de las obras en estas fuentes. 


\subsection{El orden genético en el NDHE: primera propuesta}

Además de la ordenación cronológica y por frecuencia, en el $N D H E$ se ha planteado la necesidad de aplicar otras pautas de organización de las acepciones, de tipo lógico-lingüístico. En esta ocasión se presentará una primera propuesta para la adopción del criterio genético, que atiende a las relaciones existentes entre las palabras españolas y aquellas de las que proceden. Queda pendiente, para un futuro no muy lejano, esbozar las normas que regirán la ordenación temática, más próxima, probablemente, a lo que habitualmente se ha entendido como orden lógico. En este sentido, debe recordarse que la clasificación temática de las acepciones se añade, en no pocas ocasiones, en una fase avanzada de la construcción del repertorio e, incluso, surge como un proyecto independiente ${ }^{38}$. En nuestros días construir este tipo de taxonomías exige, probablemente, intentar desarrollar sistemas basados en una ontología estándar ${ }^{39}$.

Dotar de la posibilidad de consultar los artículos de un diccionario en función de un criterio genético supone una operación previa de análisis de distintos artículos para determinar los criterios que habrán de regir este modo de presentación de las acepciones. Dado que el repertorio seguirá creciendo y evolucionando, estas pautas han de considerarse necesariamente provisionales (esto es: servirán tan solo para construir el primer prototipo de esa sección de las herramientas de redacción y visualización del diccionario). Por lo tanto, en las páginas siguientes se mostrarán algunas de las diferentes situaciones que se han detectado en este análisis, así como la propuesta de ordenación adoptada.

En el $N D H E$ se distingue entre acepciones etimológicas (es decir, heredadas de la lengua de que se ha tomado un determinado vocablo) y no etimológicas. Cierto es que, como en el caso de galápago, un porcentaje de voces no presenta una etimología segura, por lo que el criterio etimológico no se aplica; en este tipo de vocablos, la primera acepción (también en la ordenación genética) será siempre la más antigua ${ }^{40}$. Para establecer el carácter etimológico o no de una voz, se recurre a fuentes de diverso tipo (esencialmente, lexicográficas), así como a las indagaciones efectuadas en la

38 Sirva como ejemplo el Historical Thesaurus del OED, proyecto realizado en la Universidad de Glasgow, que se presenta como la organización taxonómica de los contenidos del diccionario.

39 Como punto de partida, en el NDHE se ha optado por un establecimiento gradual de taxonomías, que se van construyendo a medida que se elaboran los diferentes artículos; por ejemplo, se ha elaborado ya una primera taxonomía para los sustantivos que designan enfermedades o instrumentos musicales.

40 Según el $N D H E$ (s. v.) que, a su vez, se basa en la hipótesis apuntada en el $D E C H$ (s. v.), galápago procede probablemente «de un hispánico prerromano *calappacu». 
redacción de los artículos, pues el estudio de la documentación facilita, en muchas ocasiones, la identificación del étimo de la voz analizada ${ }^{41}$.

Un caso ligeramente diferente es el de clípeo, en el que todas las acepciones registradas se atestiguan también en la lengua madre (el latín), si bien algunas se pueden adscribir al latín científico o neolatín; la solución adoptada en este tipo de casos consiste en mantener que la ordenación genética y la cronológica no difieren. Aunque se podrían establecer mecanismos de cambio entre acepciones en la lengua madre, esa tarea excede, en nuestra opinión, la labor propia del $N D H E^{42}$.

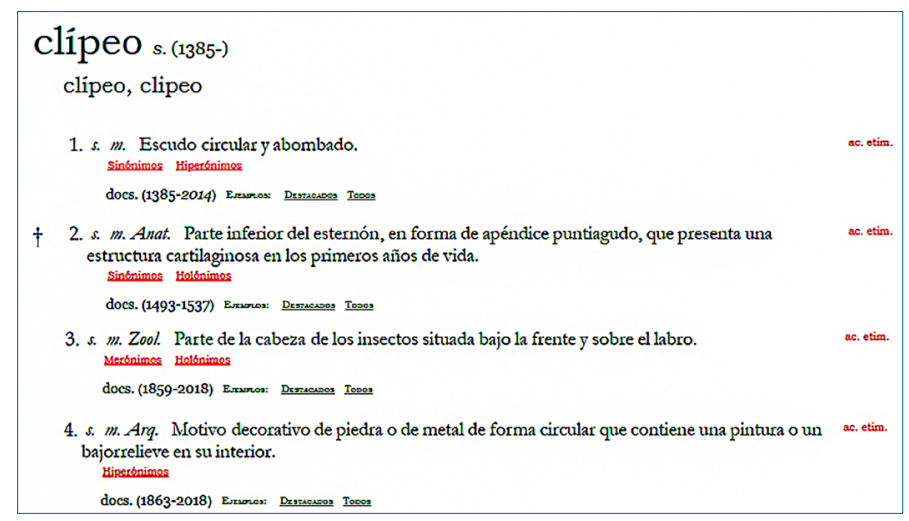

FIGURA 3. Orden genético (clípeo)

$41 \quad$ Así, por ejemplo, si bien para el francés constituyen fuentes de primer orden el $D H L F$, el TLF y el $F E W$, en artículos como guardarrayos se percibe que la hipótesis etimológica es original del NDHE, circunstancia que no es inhabitual, por los motivos expuestos arriba; en esta ocasión se indica que el primer texto que recoge la voz (publicado en el Mercurio Histórico y Politico de agosto de 1776) constituye una traducción de otro publicado, en julio de ese mismo año, en el Journal politique, ou Gazette des gazettes. Y el galicismo torpilla ('máquina bélica provista de una carga explosiva') atestiguado en español desde 1831, que el $T L F$ registra desde 1842, se localiza en francés, de acuerdo con el $N D H E$, ya en 1812; la anticipación de los primeros testimonios de otras lenguas se debe, como es evidente, a la posibilidad de acceder a nuevas fuentes tras el masivo proceso de digitalización vivido en los últimos años.

42 Evidentemente, la principal crítica que se puede realizar a este tipo de ordenación es la naturaleza limitada (o, incluso, incompleta) de la información sobre la que se basan las hipótesis etimológicas sustentadas en el NDHE; consultar un diccionario etimológico o uno histórico del alemán, del francés, del inglés, del italiano o del latín no garantiza que en ellos se hayan recogido todos los valores de la palabra en ese idioma, pero es también indiscutible que un diccionario histórico del español no puede pretender convertirse en el diccionario histórico y etimológico de todos aquellos idiomas con los que se ha relacionado nuestra lengua a lo largo de su vida. Por consiguiente, la identificación de acepciones etimológicas ha de entenderse como una propuesta interpretativa, efectuada a la luz de los datos disponibles en el momento de publicar un artículo concreto. Nada impide ir depurando y refinando, en versiones posteriores, esa sección del artículo si se obtienen nuevas informaciones. 
Por otra parte, no se nos oculta que otro problema radica en el hecho de presentar como acepciones nacidas por mecanismos de cambio en español ciertos significados que habrían podido surgir con anterioridad en la lengua de partida; así sucede, por ejemplo, en fortepiano con las acepciones 'arte o técnica de tocar el fortepiano' y 'persona que toca el fortepiano':

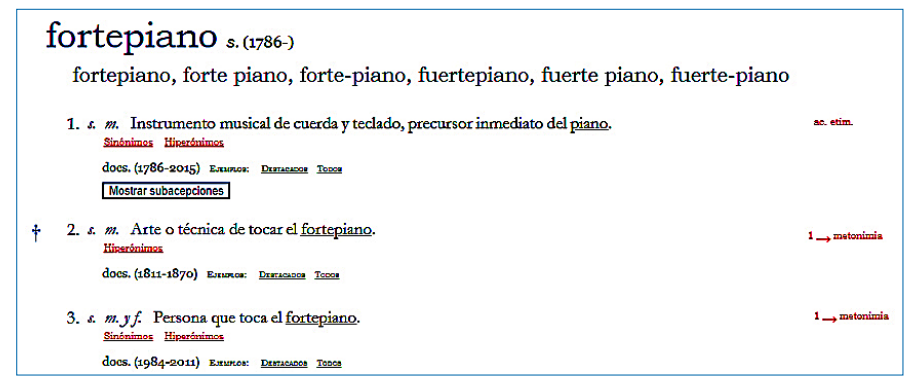

FIGURA 4. Fortepiano

No obstante, a no ser que se registre claramente ese significado previamente en la lengua suministradora del étimo inmediato (y, además, como fuente de la acepción en español), se opta por explicarlo de este modo; téngase en cuenta, además, que este tipo de acepciones metonímicas no suelen registrarse sistemáticamente en los diccionarios históricos (o, en el caso de que se consignen, su documentación es habitualmente posterior a la localizada en español).

En el NDHE se incluyen vínculos entre acepciones mediante la opción mecanismo, que sirve para indicar que una acepción procede de otra y que se ha verificado un cambio semántico; el catálogo de mecanismos de cambio que se incluye en esta sección de la herramienta de redacción está conformado por los siguientes elementos: metáfora (que comprende también la analogía), metonimia, sinécdoque, transferencia entre cohipónimos, extensión de significado, restricción de significado y conversión ${ }^{43}$.

En el caso de las voces tomadas de otras lenguas, la propuesta para establecer el orden genético consiste en incluir, en primer lugar, la acepción etimológica más antigua $\mathrm{y}$, a continuación, las acepciones vinculadas a ella por un mismo mecanismo; es decir, en realidad se propone combinar un criterio etimológico y una segunda ordenación basada en el tipo de mecanismo. Así, en bikini² (figura 5) se sitúa en primer lugar la

43 A su vez, estos cambios pueden poseer dos consecuencias: depreciación o desarrollo peyorativo y valoración o desarrollo meliorativo. 
primera acepción etimológica ('traje de baño de dos piezas para mujer'), seguida por aquellas que son el resultado de un mismo mecanismo.

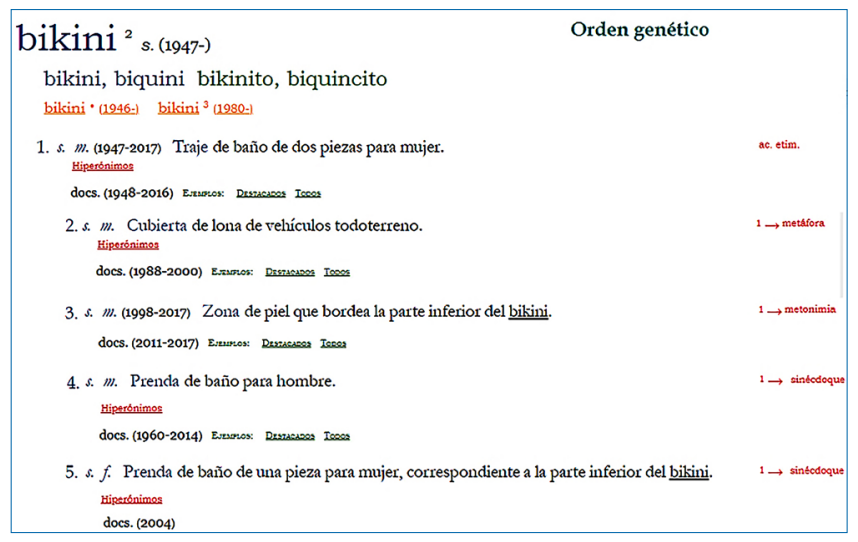

FIGURA 5. Orden genético (bikini)

Sin embargo, dado que este tipo de ordenación prima un tipo de mecanismo sobre otros, de acuerdo con una prelación establecida previamente, se dispondrá también de la opción de recurrir a un tipo de orden mixto (cronológico y genético), que situará en primer lugar la acepción etimológica que disponga del primer testimonio en español e, inmediatamente después y por orden cronológico, todas las acepciones que proceden de ella tras la actuación de algún mecanismo de cambio semántico.

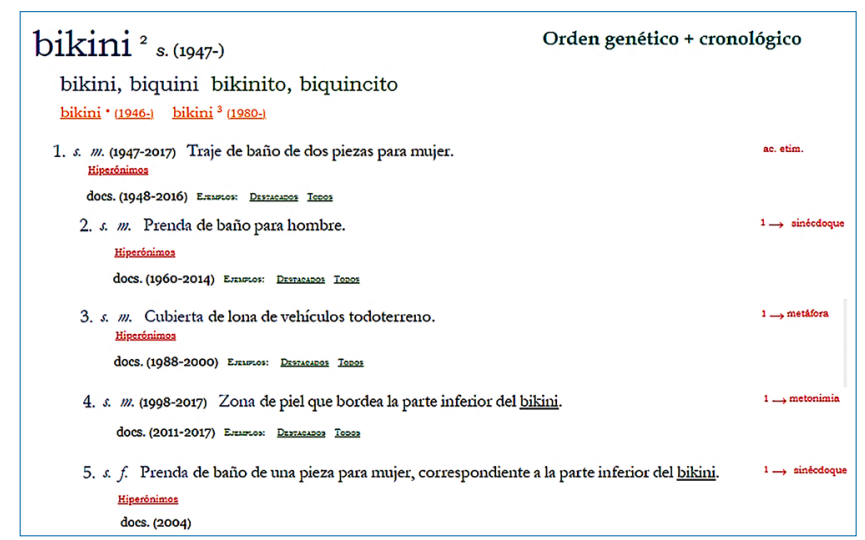

FIGURA 6. Orden genético-cronológico (bikini) 
Otro ejemplo lo facilita el artículo corsé, en que dos acepciones son etimológicas; la propuesta consiste en incorporar en primer lugar la primera acepción etimológica y, a continuación, las creadas en español a partir de ella a través de algún mecanismo (y, a continuación, las otras acepciones etimológicas).

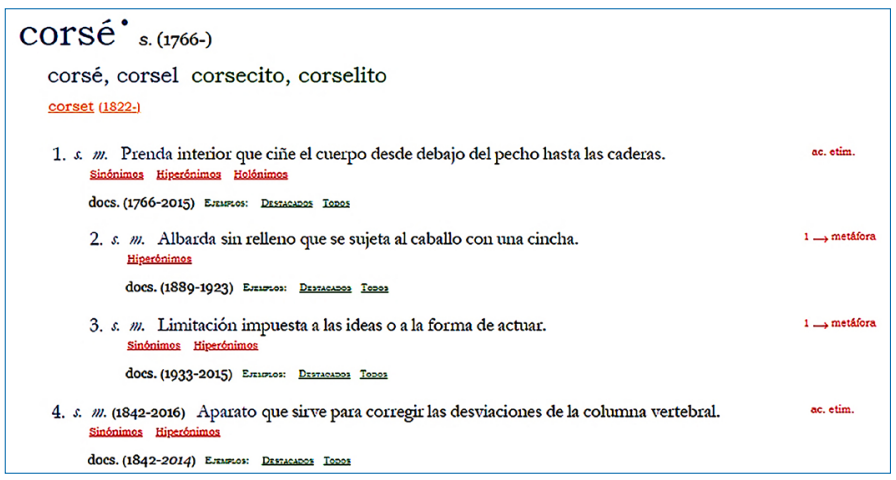

Figura 7. Corsé

No obstante, subsiste un problema importante en este capítulo, pues, como se ha indicado anteriormente, algunas etimologías se apuntan como probables, por lo que no se establece después un vínculo con el étimo probable en el nivel de la acepción; esto sucede en artículos como el consagrado a barometría ${ }^{44}$ :

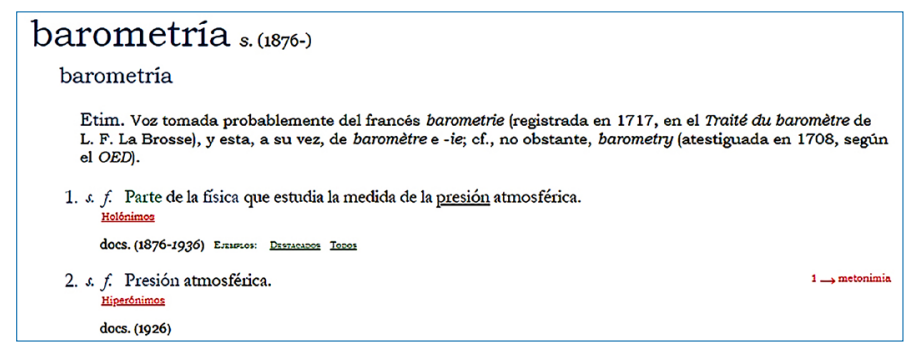

FiguRA 8. Barometría

$44 \quad$ Una posible solución sería poder representar gráficamente esa condición hipotética, no segura, del vínculo con la voz madre (y con sus acepciones). 
Para voces creadas por composición en español, la ordenación seguiría también este criterio mixto: en primer lugar, la acepción más antigua y, después, las acepciones relacionadas con ella y vinculadas por el mismo mecanismo; esto supone, por consiguiente, emplear de alguna manera un criterio cronológico. Otra opción, al igual que en el caso de bikini (figura 6), permitirá incorporar, tras la primera acepción y en sucesión cronológica, aquellas que nacen tras la actuación de cualquiera de los mecanismos identificados y que, como en el caso que nos ocupa, pueden constituir, a su vez, el origen de nuevas acepciones; así sucede con la acepción 3 de avestruz ('ave corredora, endémica de Sudamérica, parecida al avestruz, pero de menor tamaño, con el plumaje gris o pardo, sin cola, muslos provistos de plumas y tres dedos en cada pie'), que engendra, por sinécdoque, otras dos ('carne de avestruz' y 'piel de avestruz') y, por metáfora, otro nuevo significado (sinónimo de suri: 'ave corredora, endémica de Sudamérica, parecida al ñandú, pero de menor tamaño, con plumaje gris parduzco').

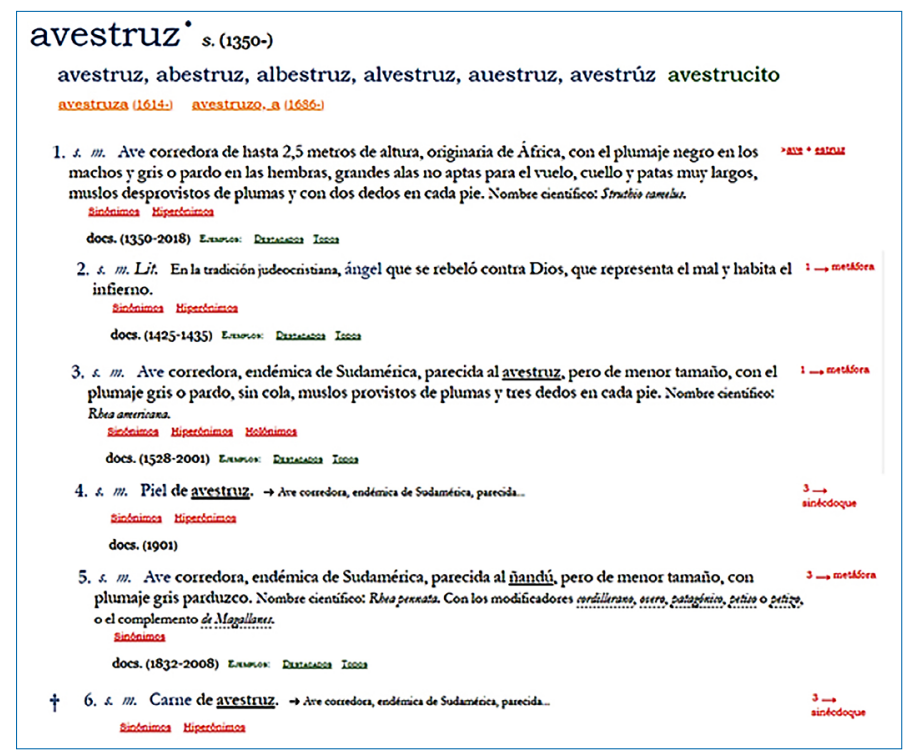

Figura 9. Avestruz

Para la aplicación del criterio genético, en el caso de voces creadas mediante distintos procedimientos de formación de palabras, deben plantearse, entre otras, las siguientes cuestiones:

a) ¿Ha de establecerse alguna prelación entre las acepciones de la palabra base? 
b) ¿Debe darse prioridad a alguno de los valores de los afijos?

c) ¿Debe atenderse a criterios categoriales como pauta de ordenación?

Para responder a estas cuestiones se proponen los ejemplos de griposo y guitarrero, a. En griposo, el sufijo -oso puede generar tanto adjetivos de posesión como adjetivos de semejanza y adjetivos relacionales (la palabra base se mantiene con el mismo significado) y solo secundariamente se entiende que, a partir del adjetivo de posesión, se puede crear el sustantivo griposo, por lo que el protocolo debe consistir, a nuestro juicio, en mantener el primer valor codificado por el afijo y no establecer prelaciones entre valores (aunque sí agrupar tras la primera acepción la del sustantivo, vinculado a ella por conversión).

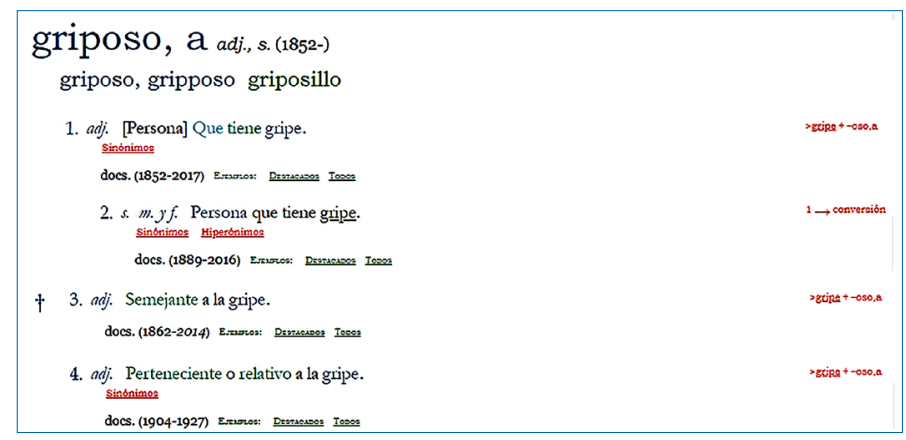

Figura 10. Griposo, a

En la imagen siguiente (figura 11) se puede percibir cómo se codifica la información morfogenética de los derivados en la herramienta de redacción (acep. 1: adjetivo de posesión; acep. 2: adjetivo de semejanza).

En guitarrero, a (figura 12), en cambio, nos encontramos, por una parte, ante un sustantivo denominal y, por otra, ante un adjetivo denominal (y ambas posibilidades son morfológicamente predecibles); como sustantivo se registra con las acepciones 'persona que toca la guitarra' (1589) y 'persona que hace, arregla o vende guitarras u otros instrumentos de cuerda' (1604), en tanto que como adjetivo se atestigua como adjetivo disposicional ('aficionado a la guitarra'; 1604) y como adjetivo relacional ('perteneciente o relativo a la guitarra'; 1908). En este tipo de artículos se opta por mantener el orden impuesto por la primera acepción documentada, incorporando después todas las acepciones (ya correspondan a adjetivos, ya a sustantivos) vinculadas con el mismo significado de la palabra base ${ }^{45}$.

$45 \quad$ Otra opción sería incluir primero los sustantivos y luego los adjetivos, pero, a nuestro juicio, debe otorgarse un carácter prioritario al hecho de que el derivado mantenga un vínculo indudable con el 


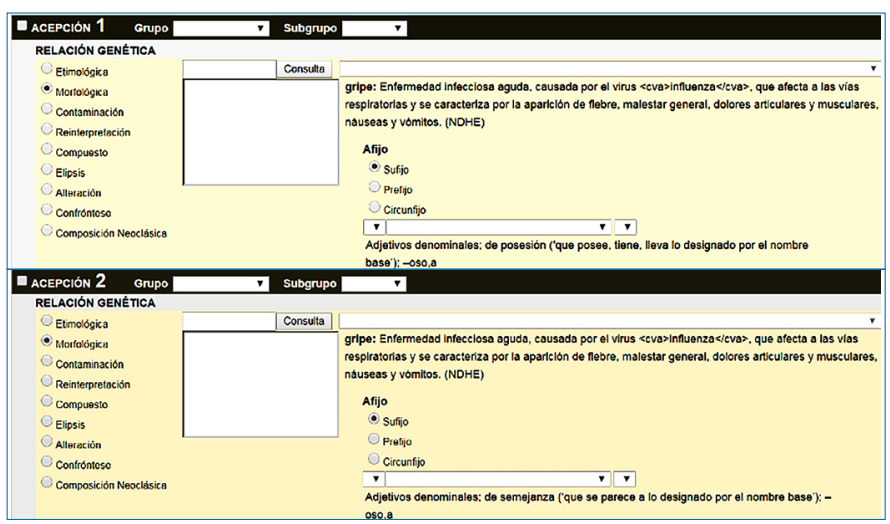

FIGURA 11. Información morfogenética de los derivados (herramienta de redacción)

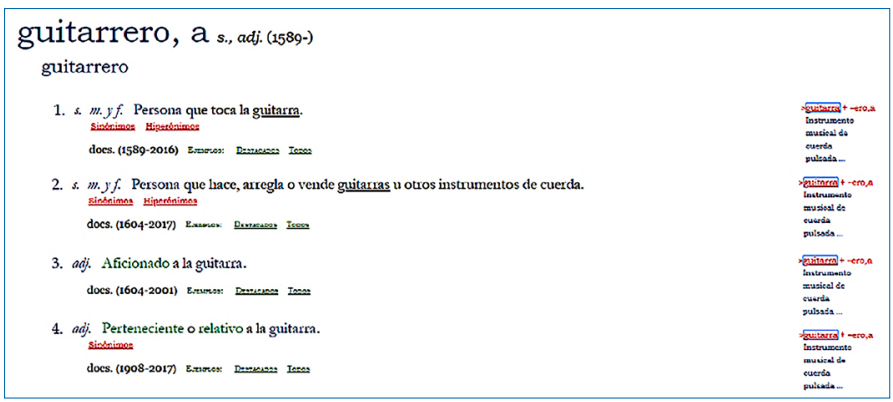

FIGURA 12. Guitarrero, a

En definitiva, esta primera aproximación a los principios estructuradores de la ordenación genética en el $N D H E$ nos permite concluir que no parecen existir criterios puros, desprovistos de la interacción con otros principios ordenadores; en el pequeño abanico de casos expuestos, el orden genético interactúa con el cronológico y el categorial. En cualquier caso, esta pauta de organización de las acepciones permitirá percibir, aunque sea con trazo grueso, las líneas generales de las continuidades y discontinuidades que, en el ámbito del significado, presentan las palabras del español con respecto a aquellas de las que proceden o derivan.

significado de la palabra base de derivación; es decir, la relación semántica entre base y derivado debe primar sobre el criterio categorial. 


\section{CONCLUSIONES}

En los repertorios lexicográficos se han empleado diversas pautas ordenadoras de las acepciones, entre las que destacan el orden cronológico o histórico, el lógico o nocional, el de frecuencia y el genético. La utilidad de cada pauta está íntimamente relacionada con el tipo de repertorio que se pretende confeccionar y con los usuarios ideales (o reales) a los que se dirige cada diccionario. Diversos estudios han mostrado las virtudes y deficiencias de estos criterios, así como la vaguedad que envuelve el uso efectivo de alguno estos principios (en particular, el lógico o nocional) en la práctica lexicográfica.

En los diccionarios históricos, publicados generalmente en papel, el protagonismo ha correspondido a los criterios cronológico y lógico-lingüístico, sin menosprecio de la utilización esporádica de otras informaciones (como las referidas a la etimología o a la frecuencia de uso). El patrón modelado por el $O E D$, que aspira a reconstruir y representar la evolución semántica de las palabras, ha determinado el desarrollo de la lexicografía histórica del español y, en particular, la arquitectura del DHLE, cuyos artículos persiguen desentrañar la red de relaciones y dependencias existentes entre los distintos significados de una voz, agrupándolos en distintas ramas semánticas, sin descuidar el criterio cronológico, que mantiene su primacía en la ordenación de los diferentes grupos identificados, así como de las acepciones incluidas en ellos.

La nueva lexicografía nos ofrece la oportunidad de dotar a los diccionarios de opciones de consulta más ricas y flexibles, de tal modo que el $N D H E$ posibilita ordenar las acepciones de los artículos en virtud de su cronología o de su frecuencia. Pese a sus posibles limitaciones y problemas, la implementación del criterio genético permitirá obtener algunos datos básicos para poder efectuar investigaciones más profundas y refinadas sobre el cambio semántico en español, así como para los estudios de formación de palabras (y de la relación derivativa) en el ámbito de la morfología léxica diacrónica del español. Y, por tanto, a pesar de su carácter provisional (y, en cierta medida, hipotético), puesto que nuevas indagaciones pueden modificar el estado actual de nuestros conocimientos sobre la etimología (y, por consiguiente, sobre qué significados hereda un determinado vocablo), esta opción de consulta podrá servir para un mejor conocimiento de la historia del léxico del español, de nuestro patrimonio léxico, que constituye, al tiempo, nuestra herencia y nuestro legado. 


\section{BIBLIOGRAFÍA}

\section{Corpus}

$C D H$. Instituto de investigación Rafael Lapesa de la Real Academia Española. 2013. Corpus del Nuevo diccionario histórico $(\mathrm{CDH})$ [en línea] http://web.frl.es/CNDHE CORDE. Real Academia Española: Banco de datos (CORDE) [en línea]. Corpus diacrónico del español. http://www.rae.es

CREA. Real Academia Española: Banco de datos (CREA) [en línea]. Corpus de referencia del español actual. http://www.rae.es

\section{Diccionarios}

DECH. Corominas, J. y J. A. Pascual (1980-1991): Diccionario crítico etimológico castellano e hispánico. Madrid: Gredos.

DHLE. Real Academia Española (1960-1996): Diccionario histórico de la lengua española. Madrid.

DHLF. Rey, A. (dir.) (1998): Dictonnaire historique de la langue française. París: Le Robert.

FEW. Wartburg, W. von (1942-2002): Französisches etymologisches Wörterbuch. Basel: Druck.

NDHE. Real Academia Española (2013-): Nuevo diccionario histórico del español. Accesible en web.frl.es/DH

OED. Murray, J. et alii (1884-1928 [1978]): The Oxford English Dictionary. Oxford: Clarendon Press.

TLF. Imbs, P. y B. Quemada (dirs.) (1971-1994): Trésor de la langue française. Paris: CNRS.

\section{Referencias bibliográficas}

Battenburg, J. D. (1991): English Monolingual Learner's Dictionaries: A useroriented study. Tübingen: Max Niemeyer.

CAmpos Souto, M. (2015): «El NDHE como muestra de la nueva lexicografía digital», Estudios de lexicografía 3, pp. 71-93. 
Campos Souto, M. (2016): «Lexicografía del futuro para la lengua del pasado», in R. Cotelo García (ed.): Entre dos coordenadas: La perspectiva diacrónica y diatópica en los estudios léxicos del español. San Millán de la Cogolla: Cilengua, pp. 33-71.

CAmpos Souto, M. (2018): «Las bases documentales del NDHE: Entre la realidad y el deseo», in D. Corbella et alii (eds.): Historia del léxico español y Humanidades digitales. Berlín: Peter Lang, pp. 19-45.

CASARES, J. (1950): Introducción a la lexicografía moderna. Madrid: Instituto Miguel de Cervantes.

Dubois, J. (1984): «Models of the Dictionary: Evolution in Dictionary Design», Applied Linguistics II (3), pp. 236-249. https://doi.org/10.1093/applin/II.3.236

GolD, D. L. (1986): «Ordering the Senses in a Monolingual Dictionary Entry», Babel 32 (1), pp. 44-49. https://doi.org/10.1075/babel.32.1.18dav

GorCY, G. (1989): «Différentiation des significations dans le dictionnaire monolingüe: problèmes et méthodes», in F. Hausmann et alii (eds.): Wörterbücher. Ein internationaels Handbuch zur Lexicographie. Berlin/New York, Walter de Gruyter, vol. 1, pp. 905-917.

Hiorth, F. (1954): «Arrangement of meanings in lexicography. Purpose, disposition and general remarks», Lingua 4, pp. 413-424. https://doi. org/10.1016/0024-3841(54)90075-3

KIPFER, B. A. (1984), «Methods of ordering senses within entries», in R. R. K. Hartman (ed.): LEXeter '83 Proceedings. Tübingen: Max Niemeyer, pp. 101-108.

LAPESA, R. (1980): «Alma y ánima en el Diccionario Histórico de la Lengua Española», Boletín de la Real Academia Española 60 (220), pp. 183-196.

LEW, R. (2009): «Towards variable function-dependent sense ordering in future dictionaries», in H. Bergentholtz, S. Nielsen y S. Tarp (eds.): Lexicography at a Crossroads: Dictionaries and Encyclopaedias Today, Lexicographical Tools Tomorrow. Berlin: Peter Lang, pp. 237-264.

LEW, R. (2013): «Identifying, ordering and defining senses», in H. Jackson (ed.): The Bloomsbury Companion to Lexicography. London: Bloombsbury Publishing, pp. 284-302.

MARCos Marín, F. (1975): «Problemas de redacción de los diccionarios históricos. El artículo accidente en el Trésor de la Langue Française y el Diccionario Histórico de la Lengua Española», Verba 2, pp. 181-188.

MoERDIKJ, F. (2003): «The codification of semantic information», in P. van Stenkenburg (ed.): A Practical Guide to Lexicography. Amsterdam: John Benjamins, pp. 273-296. https://doi.org/10.1075/tlrp.6.32moe 
Moliner, M. (1966 [1990]): «Presentación», in M. Moliner: Diccionario de uso del español. Madrid: Gredos.

MurRAY, J. et alii (1884 [1978]): «General explanations», in J. Murray et alii, The Oxford English Dictionary. Oxford: Clarendon Press, pp. VII-XIV.

Pascual Rodríguez, J. A. y R. García Pérez (2007): Límites y horizontes en un diccionario histórico. Salamanca: Diputación de Salamanca.

PASCUAL, J. A. (2015): «Introducción a una celebración lexicográfica: a propósito de la reciente publicación de un millar de palabras del $N D H E$ en el portal de la RAE», Estudios de lexicografía 3, pp. 7-13.

PASCuAL, J. A (2016): «La Filología en vago y en vilo entre los datos», in E. Blanco (coord.): Grandes y pequeños de la literatura medieval y renacentista. Salamanca: Ediciones del Semyr, pp. 55-84.

Porto Dapena, J. Á. (2002): Manual de técnica lexicográfica. Madrid: Arco/Libros. RAFEL I FontANALS, J. (2005): Lexicografia. Barcelona: UOC.

Rodríguez Molina, J. y A. Octavio de Toledo y Huerta (2017): «La imprescindible distinción entre texto y testimonio: el CORDE y los criterios de fiabilidad lingüística». Scriptum Digital 6, pp. 5-68.

Rojo, G. (2009): «Sobre la construcción de diccionarios basados en corpus», Tradumàtica: Traducció i tecnologies de la información i la comunicació 7. [Accesible en https://www.raco.cat/index.php/Tradumatica/article/view/154829]. Salas Quesada, P. y A. Torres Morcillo (2011): «ARDIDEs: Aplicación de Redacción de un Diccionario Diacrónico del Español». Revista de lexicografía XVII, pp. 133-159.

Salas Quesada, P. y A. Torres Morcillo (2015): «Aproximación a los fundamentos del NDHE a través de las herramientas informáticas usadas en su elaboración y presentación». Estudios de lexicografia 3, pp. 15-69.

Seco, M. (1980): Las palabras en el tiempo: los diccionarios históricos. Madrid: Real Academia Española.

SECO, M. (1995): «El diccionario histórico de la lengua española». International Journal of Lexicography 8 (3), pp. 203-219.

SiLva, P. (2000): «Time and Meaning: Sense and Definition in the $O E D »$, in L. Mugglestone (ed.): Lexicography and the OED: Pioneers in the Untrodden Forest. Oxford: Oxford University Press, pp. 77-95. 